\title{
A Compact Microstrip Lowpass Filter with Ultra-Wide Rejection Band and Sharp Transition Band Utilizing Combined Resonators with Triangular Patches
}

\author{
Ashkan ABDIPOUR, Arash ABDIPOUR, Amir KHOSRAVI \\ Young Researchers and Elite Club, Kermanshah Branch, Islamic Azad University, Kermanshah, Iran \\ Ashkan_abdipour@yahoo.com, Arash.abdipour@yahoo.com \\ Submitted November 20, 2017 / Accepted April 13, 2018
}

\begin{abstract}
In this paper, a microstrip lowpass filter with $-3 \mathrm{~dB}$ cut-off frequency of $1.8 \mathrm{GHz}$ consisting of two resonators with different triangular patches and four high-low impedance resonators as suppressing cells has been designed. To design this filter, the influence of each transmission line on the frequency response of the utilized resonators has been clarified by calculating the equations of $S_{21}$ and $S_{11}$ based on the lumped circuit of them separately. The designed filter has been constructed and tested, and a good agreement between the simulation and measurement results has been achieved. The stopband covers an ultra-wide frequency range from 1.94 to $34.556 \mathrm{GHz}$ with a suppression level of $-21.2 \mathrm{~dB}$. Furthermore, the insertion loss in the passband region is close to zero from $D C$ to $1.68 \mathrm{GHz}$ and an acceptable return loss $(17.44 \mathrm{~dB})$ in this band can prove desired in-band character. Moreover, the proposed filter provides a sharp transition band equal to $228 \mathrm{~dB} / \mathrm{GHz}$. The designed lowpass filter has a high figure of merit equal to 26583.4 .
\end{abstract}

\section{Keywords}

Microstrip lowpass filter, insertion loss, return loss, triangular patches

\section{Introduction}

Microstrip lowpass filters (LPFs) are one of the most important blocks which are employed widely in wireless communication systems. Thus, various miniaturized LPFs have been presented to obtain a desired frequency response. For instance, in [1], a microstrip lowpass filter with quasi-elliptic response employing both loaded radial-shape patches and meandered main transmission line has been presented. Although, this circuit has a gradual transition band and low level of stopband suppression. To widen the stopband bandwidth in the frequency response of LPFs, hairpin resonators can be used [2-6]. By employing this cell in [2], the stopband has been widened, even though, the circuit size is large and the transition band is not de- sired. A technique to design a LPF with wide stopband is utilizing stepped impedance hairpin resonator with radial stubs, which has been reported in [3], but this filter does not have a sharp transition band. In [4], by adopting stepped impedance hairpin units a compact LPF has been designed, but, this filter suffers from a narrow stopband. In [5], another technique to design a LPF on the basis of an application of shunt open-stubs coupled-line in the structure of hairpin unit has been reported. However, the proposed filter has a gradual transition band and also a large occupied area. In [6], defected ground structure (DGS) as another method is utilized to propose a LPF with sharp rejection. However, the proposed filter cannot be usable on the metal surface. To design a LPF rat-race directional couplers have been employed to function as bandstop transversal filtering sections (TFSs), in [7]. Although, adopting this method increases the circuit size significantly and also the stopband has not been expanded enough. In [8], a quasi- $\pi$-slot resonator and open stubs is adopted and a LPF with sharp skirt performance is designed, however, the occupied area is relatively large. A microstrip LPF by employing triangular and radial patch resonators has been proposed [9], but this filter has a gradual transition band. A LPF with wide stopband utilizing a cascaded microstrip coupled-line hairpin unit and semicircle stepped-impedance shunt stubs have been designed in [10]. In [11], LC resonant structures and transformed radial stubs have been used to design a LPF, but, the circuit size of both filters introduced in [10] and [11] are relatively large. Two other methods to present a LPF with sharp transition band are employing asymmetric high-low impedance patches and LC tank resonators, which has been introduced in [12] and [13], respectively. In [14], a lowpass filter using polygon patch resonant cells, T-shaped resonators and two different suppressing cells has been designed, however, this filter does not have a sharp transition band. In [15], a LPF composing of two main resonators with polygon patches and six suppressing cells to omit spurious frequencies in the stopband has been proposed, but this filter occupies a large area.

In this paper, a compact lowpass filter (LPF) with $-3 \mathrm{~dB}$ cut-off frequency of $1.8 \mathrm{GHz}$ has been designed. The 
proposed LPF is consisted of two resonators with different triangular patches and four high-low impedance resonators as suppressing cells to omit the aforementioned defects of the scattering parameters.

\section{The Procedure of Designing}

The configuration of the primary resonator utilizing triangular patch and its lumped circuit are depicted in Fig. 1(a) and (b). As it is observed from Fig. 1(b), the inductance L2 account for the transmission lines determined by TL1 in Fig. 1(a). The triangular patch and high impedance transmission line determined by TL2 have been modeled by the shown capacitance $\mathrm{C}_{1}$ and inductor $\mathrm{L}_{1}$, respectively. $\mathrm{C}_{2}, \mathrm{C}_{3}$ and $\mathrm{C}_{4}$ present the capacitance between the microstrip structure and the ground.

To understand the effects of variables on the frequency response, the equations of $S_{21}$ " and $S_{11}$ " of the resonator illustrated in Fig. 1(a) on the basis of its LC circuit have been extracted. The ABCD parameters of a twoport network are given by [16]:

$$
\begin{gathered}
A=\frac{\omega^{2} C_{1} L_{2}}{\omega^{2} C_{1} L_{2}-1}+1, \\
B=\frac{\mathrm{j} \omega^{2} L_{2}^{2} C_{1}+2 \mathrm{j} \omega L_{2}\left(\omega^{2} L_{1} C_{1}-1\right)}{1-\omega^{2} C_{1} L_{1}}+1, \\
C=\frac{\mathrm{j} \omega C_{1}}{1-\omega^{2} C_{1} L_{1}}, \\
D=\frac{\omega^{2} L_{2} C_{1}}{\omega^{2} C_{1} L_{1}-1}+1 .
\end{gathered}
$$

According to the obtained parameters of transfer matrix, the equations of $S_{21}$ " and $S_{11}$ " of the primary resonator are as follows [16]:

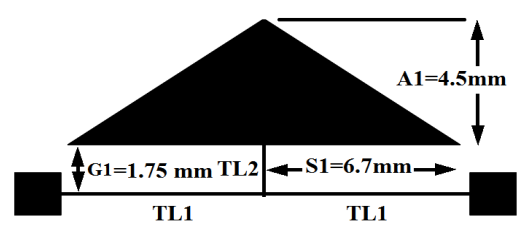

(a)

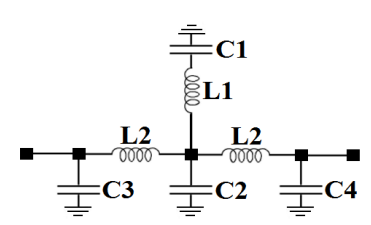

(b)

Fig. 1. (a) The configuration of the primary resonator with triangular patch. (b) Its equivalent LC circuit. (c) The EM simulation result and the frequency response of LC circuit of the primary structure.

$$
\begin{gathered}
S_{11}^{\prime \prime}=\frac{A+\frac{B}{Z_{0}}-C Z_{0}-D}{A+\frac{B}{Z_{0}}+C Z_{0}+D}, \\
S_{22}^{\prime \prime}=\frac{-A+\frac{B}{Z_{0}}-C Z_{0}+D}{A+\frac{B}{Z_{0}}+C Z_{0}+D}, \\
S_{12}^{\prime \prime}=\frac{2(A D-B C)}{A+\frac{B}{Z_{0}}+C Z_{0}+D}, \\
S_{12}^{\prime \prime}=\frac{2}{A+\frac{B}{Z_{0}}+C Z_{0}+D} .
\end{gathered}
$$
follows:

Thus, the scattering parameters can be calculated as

$$
\begin{gathered}
S_{11}^{\prime \prime}=\frac{-s^{3} L_{2} C_{1}\left(L_{2}+2 L_{1}\right)-s L_{2}\left(L_{2}+C_{1}\right)}{2 Z_{0} X_{1}+s^{3} X_{2}-s L_{2}\left(L_{2}+C_{1}\right)}, \\
S_{21}^{\prime \prime}=\frac{2 Z_{0}\left(1+s^{2} C_{1} L_{1}\right)}{2 Z_{0} X_{1}-s^{3} X_{2}-s L_{2}\left(L_{2}+C_{1}\right)}, \\
X_{1}=\left(1+s^{2} C_{1} L_{2}+s^{2} C_{1} L_{1}\right), \\
X_{2}=L_{2} C_{1}\left(1+2 L_{1}\right) .
\end{gathered}
$$

According to (9) and (10), to control $S_{21}$ " and $S_{11}$ " the values of $L_{1}$ and $C_{1}$ can be changed.

As it has been shown in Fig. 1(a) and (b), the triangular patch and the high-impedance transmission line determined by TL2 have been modeled by these lumped elements, respectively. Therefore, to explain how they affect the frequency response, their corresponding microstrip realizations can be utilized, instead. Therefore,
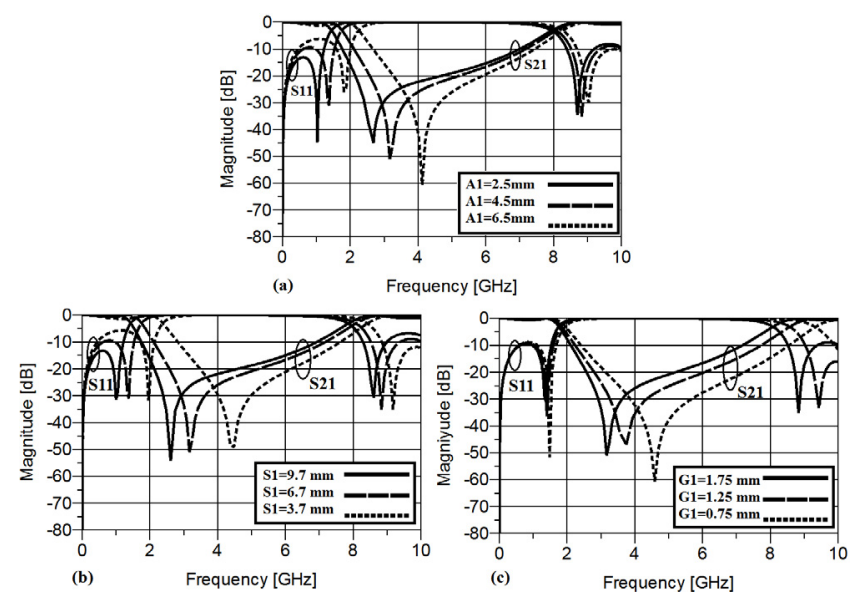

Fig. 2. The behavior of the main resonator against changing the values of S1, G1 and A1. 
several full-wave simulations versus $A_{1}, S_{1}$ and $G_{1}$ have been plotted in Figs. 2(a), (b) and (c), respectively. According to Fig. 2, by increasing the values of these three variables, the transition zero will move to lower frequencies leading to a sharper skirt performance. Moreover, these increases result in decreasing the return loss level in the pass band. Note that, by changing the values of $S_{1}$, from 3.7 to $9.7 \mathrm{~mm}$ with steps of $3 \mathrm{~mm}$, and also the value of $A_{1}$ from 2.5 to $6.5 \mathrm{~mm}$ with steps of $2 \mathrm{~mm}$, the $-3 \mathrm{~dB}$ cut-off frequency will move toward lower frequencies, significantly. The values of lumped elements of the depicted LC circuit in Fig. 2(b) are [16]: $L_{1}=1.514 \mathrm{nH}$, $C_{1}=1.62 \mathrm{pF}, L_{2}=7.228 \mathrm{nH}, \quad C_{2}=0.449 \mathrm{pF}$ and $C_{3}=$ $C_{4}=0.0012 \mathrm{pF}$. The values of inductors and capacitances have been obtained based on RO4003 substrate with a thickness of $0.508 \mathrm{~mm}$ and the permittivity of 3.38. Figure 1(c) illustrates the EM simulation and the frequency response of LC circuit of the primary resonator, which are in good agreement. According to the simulated results of the resonator in Fig. 1(c), the return loss and insertion loss in the passband are better than 0.512 and $9.379 \mathrm{~dB}$, respectively. In addition, this resonator creates a transition zero at $3.206 \mathrm{GHz}$ with an attenuation level of $-53.855 \mathrm{~dB}$ bringing about a rejection level of $-15 \mathrm{~dB}$ from 2.338 to $6.358 \mathrm{GHz}$. As it can be seen, the mentioned resonator suffers from an undesired transition band and narrow stopband bandwidth.

The structure of the first main resonator utilizing two primary resonators that are placed symmetrically around (X) axis and its equivalent lumped circuit have been illustrated in Figs. 3(a) and (b), respectively. Similar to the primary resonance cell, to find the effects of each microstrip line on the s-parameters, the equations of $S_{21}$ and $S_{11}^{\prime}$ of the resonance unit shown in Fig. 3(a) based on its LC circuit have been calculated as follows:

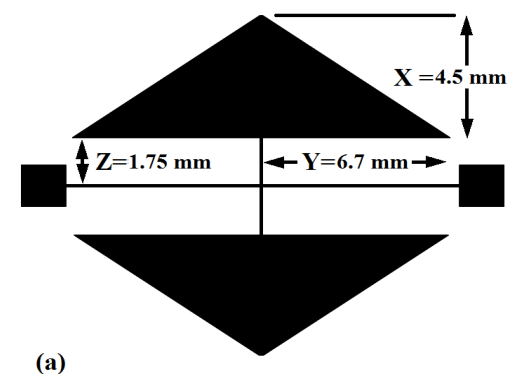

(a)

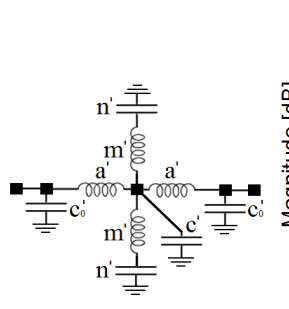

(b)

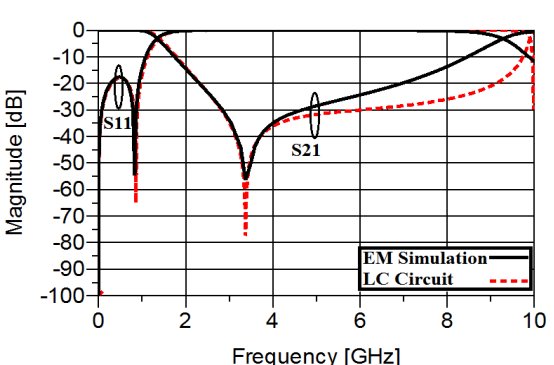

(c)

$$
\begin{aligned}
& S_{11}^{\prime}=\frac{2 a^{\prime} x^{\prime} s+y^{\prime} a^{\prime 2} s^{2}-y^{\prime} Z_{0}{ }^{2}}{2 Z_{0}\left(x^{\prime}+a^{\prime} y^{\prime} s\right)+y^{\prime} a^{\prime 2} s^{2}+y^{\prime} Z_{0}^{2}}, \\
& S_{21}^{\prime}=\frac{2 x^{\prime} Z_{0}}{2 Z_{0}\left(x^{\prime}+a^{\prime} y^{\prime} s\right)+y^{\prime} a^{\prime 2} s^{2}+y^{\prime} Z_{0}^{2}}, \\
& x^{\prime}=\left(1+m^{\prime} n^{\prime} s^{2}\right), \\
& y^{\prime}=\left[\left(1+m^{\prime} n^{\prime} c^{\prime} s^{3}\right)+\left(c^{\prime}+2 n^{\prime}\right) s\right] .
\end{aligned}
$$

Obviously, the scattering parameters can be controlled by changing the values of $m^{\prime}$ and $n^{\prime}$. In order to present how changing the dimensions of their corresponding microstrip realizations can influence the frequency response, several full-wave simulations versus $A_{1}{ }^{\prime}, B^{\prime}$ and $G^{\prime}$ have been shown in Figs. 4(a), (b) and (c), respectively. In this case the remaining dimensions in Fig. 3(a) have been kept constant.

As it is observed from Fig. 4(a) and (b), by enhancing the value of $X$ from 2.5 to $6.5 \mathrm{~mm}$ with steps of $2 \mathrm{~mm}$ and also the value of $Y$ from 3.7 to $9.7 \mathrm{~mm}$ with steps of $3 \mathrm{~mm}$, the transition zero at $4.38 \mathrm{GHz}$ will move to lower frequencies causing a sharper transition band and improve the return loss level significantly in the passband. Moreover, the $-3 \mathrm{~dB}$ operating frequency of the resonator will move toward lower frequencies. Moreover, as it can be seen from Fig. 4(c), increasing the value of $Z$ from 0.75 to $1.75 \mathrm{~mm}$ with steps of $0.5 \mathrm{~mm}$, the transmission zero at $4.86 \mathrm{GHz}$ will shift toward the operating frequency making the transition band sharper, without any noticeable effect on the return loss in the pass band.

Eventually, the main resonance cell operating at $1.354 \mathrm{GHz}$ has been obtained. According to the illustrated EM simulation result in Fig. 3(c), the stopband of the main resonator can cover a frequency range from 1.986 up to $7.934 \mathrm{GHz}$ with a suppressing level of $-15 \mathrm{~dB}$. Furthermore, this resonator has a transition zero (TZ) at $3.372 \mathrm{GHz}$ with corresponding attenuation level of $-56.45 \mathrm{~dB}$ creating a gradual transition band. The values of lumped elements of the shown lumped LC circuit in Fig. 3(b) are [16]: $\quad C_{0}^{\prime}=0.001 \mathrm{pF}, \quad C^{\prime}=0.449 \mathrm{pF}$, $a^{\prime}=7.228 \mathrm{nH}, n^{\prime}=1.47 \mathrm{pH}, m^{\prime}=1.514 \mathrm{nH}$.
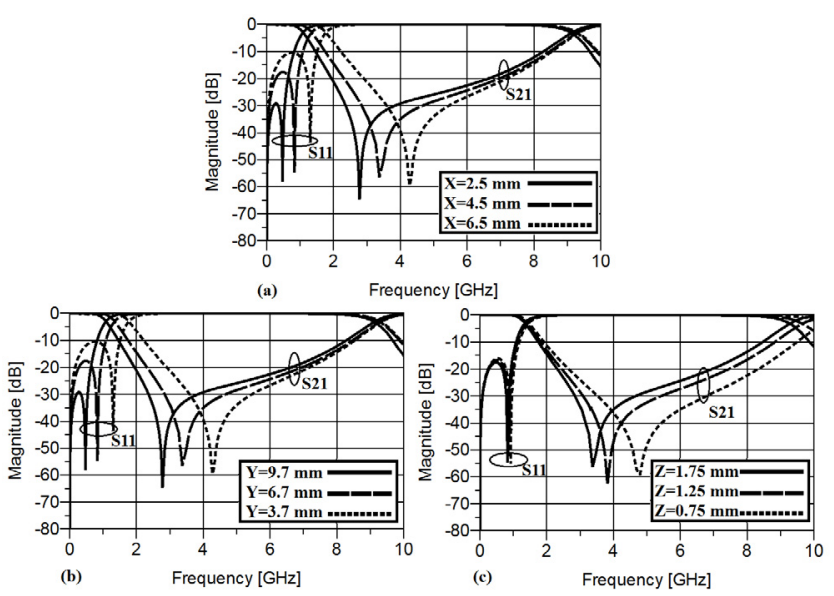

Fig. 4. The behavior of the main resonator against changing

the values of (a) X, (b) $\mathrm{Y}$ and (c) $\mathrm{Z}$. two triangular patches. (b) Its equivalent lumped circuit. (c) The EM simulation result and the frequency response of LC circuit of the main structure. 


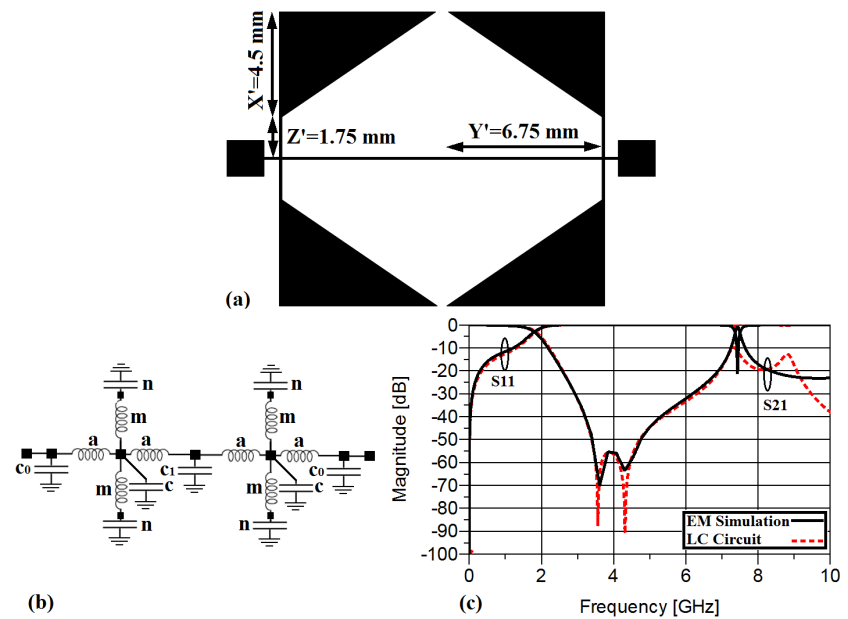

Fig. 5. (a) The configuration of the second main resonator. (b) The lumped circuit of the second resonator. (c) The EM simulation and the frequency response of the lumped circuit of the second resonator.
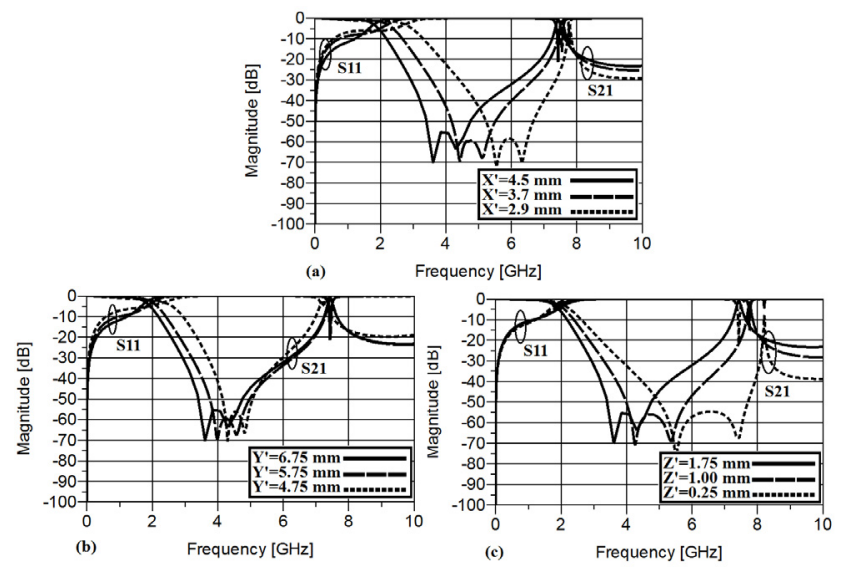

Fig. 6. The behavior of the main resonator against changing the values of: (a) $\mathrm{X}^{\prime}$, (b) $\mathrm{Y}^{\prime}$ and (c) $\mathrm{Z}^{\prime}$.

The structure of the second main resonance cell consisting of four high-low impedance resonators with rectangular patches and its equivalent lumped circuit have been depicted in Fig. 5(a) and (b), respectively. Similar to the first resonance cell, the impact of each microstrip line on controlling the scattering parameters has been determined by calculating the equations of the $S_{21}$ and $S_{11}$ of this resonator based on its LC circuits as follows:

$$
\begin{gathered}
S_{11}=\frac{4 Z_{0}^{2} x^{2} B^{\prime 2} A^{\prime \prime}+A^{\prime} D^{\prime 2}\left(B^{\prime} B^{\prime \prime}-A^{\prime} A^{\prime \prime}\right)}{B^{\prime}\left(B^{\prime} B^{\prime \prime} D^{\prime 2}-A^{\prime} D^{\prime 2} A^{\prime \prime}\right)}, \\
S_{21}=\frac{8 Z_{0}^{3} u^{2} x B^{\prime} B^{\prime \prime}}{1-A^{\prime} A^{\prime \prime} D^{\prime} D^{\prime \prime}}, \\
A^{\prime}=2 a x s+y a^{2} s^{2}-y Z_{0}^{2}, \\
D^{\prime}=B^{\prime}=\left[2 a x s+y a^{2} s^{2}+y Z_{0}^{2}+2 Z_{0} x+2 Z_{0} a y s\right], \\
A^{\prime \prime}=2 a u s+w a^{2} s^{2}-w Z_{0}^{2}, \\
D^{\prime \prime}=B^{\prime \prime}=\left[2 a u s+w a^{2} s^{2}+w Z_{0}^{2}+2 u Z_{0}+2 Z_{0} a w s\right],
\end{gathered}
$$

$$
\begin{gathered}
x=\left(1+m n s^{2}\right), \\
y=\left[\left(1+m n c s^{3}\right)+(c+2 n) s\right], \\
u=\left(1+m n s^{2}\right), \\
w=\left[\left(1+m n c s^{3}\right)+(c+2 n) s\right] .
\end{gathered}
$$

As can be seen from (17-26), $S_{21}$ and $S_{11}$ of the illustrated resonator in Fig. 5(a) can be controlled by changing the values of lumped elements. For example, according to the extracted equations, i.e. $S_{21}$ and $S_{11}, m$ and $n$ play key roles in the performance of this resonator. To justify the influence of changing $m$ and $n$ on the simulation results, their corresponding microstrip realizations can be utilized instead. Thus, several full-wave simulations versus $X^{\prime}, Y^{\prime}$ and $Z^{\prime}$ have been plotted in Fig. 6 . The behavior of the designed resonator against changing the values of $X^{\prime}, Y^{\prime}$ and $Z^{\prime}$ have been shown in Figs. 6(a) and (b). Obviously, by enhancing the values of the mentioned variables, the first transition zero will move to lower frequencies sharpening the transition band. Moreover, these increases make the return loss level better in the passband region, but not significantly. As it can be seen, by increasing the value of $X^{\prime}$ and $Y^{\prime}$ with steps of $0.8 \mathrm{~mm}$ and $1 \mathrm{~mm}$, respectively, the $-3 \mathrm{~dB}$ operating frequency will approach to lower frequencies. Although, the increase of $Z^{\prime}$ does not influence the operating frequency noticeably. Finally, a resonance cell utilizing four resonators with triangular patches has been designed. The dimensions of the resonator have been shown in Fig. 5(a). The values of the lumped elements of the shown equivalent LC in Fig. 5(b) are: $C_{0}=0.28 \mathrm{pF}$, $C=0.5 \mathrm{nH}, \quad C_{1}=0.609 \mathrm{pF}, \quad a=3.367 \mathrm{nH}, \quad n=0.71 \mathrm{pF}$, $m=2.287 \mathrm{nH}$. The EM simulation and the frequency response of the equivalent LC circuit of the second resonator operating at $1.8 \mathrm{GHz}$ have been illustrated in Fig. 5(c), which are in good agreement. According to the shown frequency response of this resonator, the insertion loss in the passband is almost zero from DC up to $1.281 \mathrm{GHz}$. Furthermore, the mentioned resonance cell makes a pair of transition zeros at $3.611 \mathrm{GHz}$ and $4.306 \mathrm{GHz}$ (TZ2) with attenuation levels of $-70.231 \mathrm{~dB}$ and $-63.641 \mathrm{~dB}$, respectively, bringing about a rejection band of $-24 \mathrm{~dB}$ from $2.569 \mathrm{GHz}$ to $6.884 \mathrm{GHz}$.

In the following stage, to expand the stopband, four suppressing cells can be employed. Employing these suppressing units leads to making some transmission nulls, thus transmission peaks will be suppressed and consequently the stopband region will be widened.

The traditional suppression unit to expand the stopband is high-low impedance resonator. The schematic of the employed suppressing unit and its equivalent LC circuit are depicted in Fig. 7(a) and (b), respectively. As it is observed, low impedance transmission lines (TL3) can be modeled by a capacitance $C_{\mathrm{s} 1}$. $L_{\mathrm{s} 1}$ and $L_{\mathrm{s} 2}$ account for the transmission lines determined by TL4 and TL5 in Fig. 7(a), respectively. $C_{\mathrm{gs}}$ is the coupling effect created by the gaps 


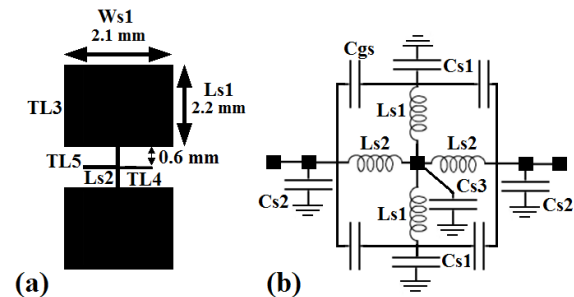

(a)

(b)

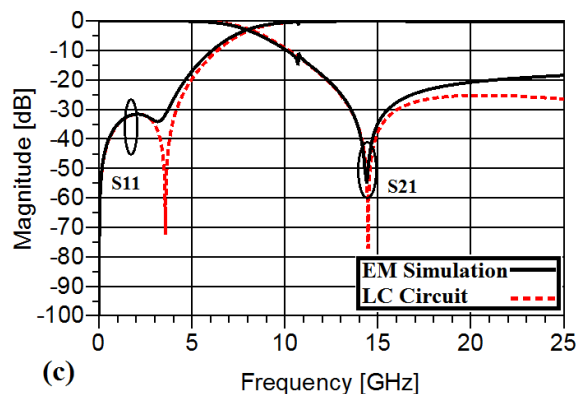

Fig. 7. (a) The configuration the employed suppressing unit. (b) The equivalent. (c) The EM simulation.
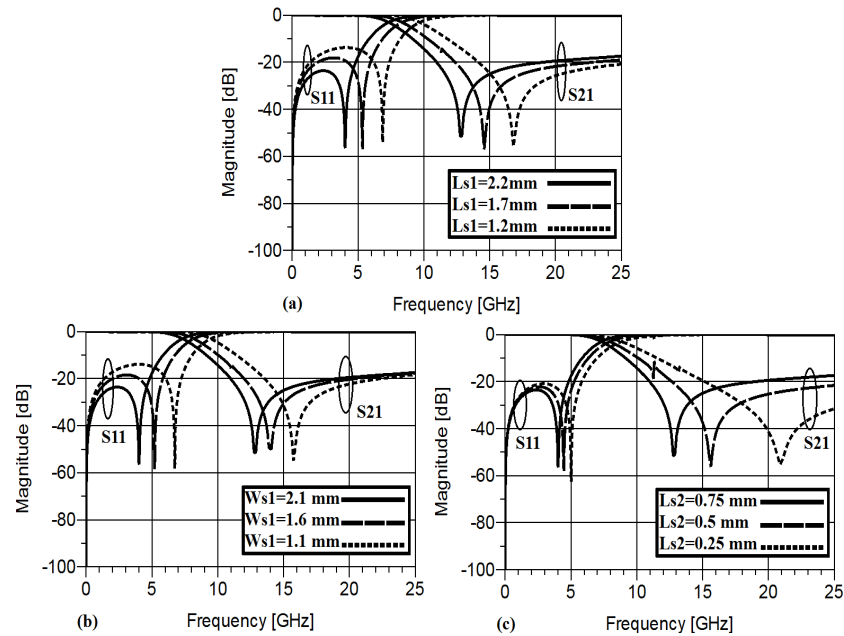

Fig. 8. The behavior of the designed suppressing cell against changing the value of (a) Ls1, (b) Ws1 and (c) Ls2.

between TL3 and TL5, which this coupling effect is trivial. $C_{\mathrm{s} 2}$ and $C_{\mathrm{s} 3}$ model the capacitance between the microstrip structure and the ground. To clarify how the frequency response and in particular the location of the transmission zeros of this suppressing unit can be controlled, the equations of $S_{21}$ and $S_{11}$ have been extracted. The scattering parameters of this resonator and its transmission zero are given by (27-32), as follows:

$$
\begin{aligned}
& S_{11}=\frac{\left(Y_{0}-Y_{11}\right)\left(Y_{0}-Y_{22}\right)+Y_{12} Y_{21}}{\left(Y_{0}+Y_{11}\right)\left(Y_{0}+Y_{22}\right)-Y_{12} Y_{21}}, \\
& S_{21}=\frac{\left(Y_{0}-Y_{11}\right)\left(Y_{0}-Y_{22}\right)+Y_{12} Y_{21}}{\left(Y_{0}+Y_{11}\right)\left(Y_{0}+Y_{22}\right)-Y_{12} Y_{21}}, \\
& F_{z}=\frac{1}{2 \pi \sqrt{2}} \sqrt{\frac{Q_{1}}{Q_{2}}+\frac{\sqrt{Q_{1}^{2}-4 Q_{3} Q_{4}}}{Q_{2}}},
\end{aligned}
$$

$$
\begin{gathered}
Q_{1}=\frac{C_{\mathrm{s} 3}}{2 C_{\mathrm{gs}}}+\frac{C_{\mathrm{s} 1} L_{\mathrm{s} 1}}{L_{\mathrm{s} 2} C_{\mathrm{gs}}}+\frac{2 L_{s 1}}{L_{\mathrm{s} 2}}, \\
Q_{2}=C_{\mathrm{s} 3}+\frac{C_{\mathrm{s} 1} C_{\mathrm{s} 3} L_{s}}{2 C_{\mathrm{gs}}}, \\
Q_{2}=\frac{1}{L_{\mathrm{s} 2} C_{\mathrm{gs}}} .
\end{gathered}
$$

According to (27-32), the location of transmission zero can be controlled by $C_{\mathrm{gs}}, C_{\mathrm{s} 1}$ and $L_{\mathrm{s} 1}$ more effectively than other capacitances and inductors. Thus, several fullwave simulations versus their corresponding microstrip realizations, which are determined by $L_{\mathrm{s} 1}, W_{\mathrm{s} 1}$ and $L_{\mathrm{s} 2}$ in Fig. 7(a), have been plotted in Fig. 8. By increasing the value of $L_{\mathrm{s} 1}$ from 1.2 to $2.2 \mathrm{~mm}$ with steps of $0.5 \mathrm{~mm}$, the transition zero will move to lower frequencies, which leads to a wider stopband region. Similarly, enhancing the value of $L_{\mathrm{s} 2}$ from 0.25 to $0.75 \mathrm{~mm}$ with steps of $0.25 \mathrm{~mm}$, will improve the wideness of the stopband, however, the rejection level decreases. The obtained values of the lumped elements of the proposed suppressing cell are optimized as follows [12]: $\quad C_{\mathrm{s} 1}=0.305 \mathrm{pF}, \quad C_{\mathrm{s} 2}=0.012 \mathrm{pF}, \quad C_{\mathrm{s} 3}=$ $0.021 \mathrm{pF}, \quad C_{\mathrm{gs}}=0.02 \mathrm{pF}, \quad L_{\mathrm{s} 1}=0.16 \mathrm{nH}, \quad L_{\mathrm{s} 2}=0.996 \mathrm{nH}$. Finally, by combining the introduced resonators and suppressing cells a lowpass filter with sharp roll-off and ultrawide stopband at $1.8 \mathrm{GHz}$ has been designed, as it can be seen in Fig. 9. The procedures of combining the utilized resonators and the influence of adding each resonator on the frequency response have been illustrated in Fig. 10(a), (b) and (c), step by step. As it can be seen from Fig. 10(a), the first resonator has a $-3 \mathrm{~dB}$ operating frequency at $1.357 \mathrm{GHz}$ and a transmission zero at $3.373 \mathrm{GHz}$ with attenuation level of $-56.453 \mathrm{~dB}$. Furthermore, in this resonator a stopband from 2.173 up to $7.188 \mathrm{GHz}$ with corresponding suppressing level better than $-17 \mathrm{~dB}$ has been achieved. Although, the first resonator suffers from a gradual transition band and narrow stopband bandwidth. In order to make the skirt performance better, four resonators with triangular patches as second main resonators are added, as shown in Fig. 10(b). The combination of resonator 1 and 2 creates two transmission zeros at 2.975 and $2.205 \mathrm{GHz}$ with corresponding attenuation levels of $-74.983 \mathrm{~dB}$ and $-41.101 \mathrm{~dB}$, respectively. In fact, by adding resonator 2 the transition zero of resonator $1, \mathrm{TZ} 1$, has been shifted toward the operating frequency and also TZ2 has been made. Shifting TZ1 to lower frequencies creates a sharp transition band about $0.35 \mathrm{GHz}$ from -3 to $-40 \mathrm{~dB}$. Note that the stopband bandwidth is not wide enough. To expand the stopband region with a high suppressing level, four high-low impedance resonator as suppressing cells can be utilized, as illustrated in Fig. 10(c). Combining resonators 1, 2 and these suppressing cells, demonstrates stopband rejection up to $18.64 f_{\text {c }}$, i.e. $32.63 \mathrm{GHz}$ with a suppressing level better than $-20 \mathrm{~dB}$. Furthermore, the insertion loss less than $0.07 \mathrm{~dB}$ and return loss better than $17 \mathrm{~dB}$ 


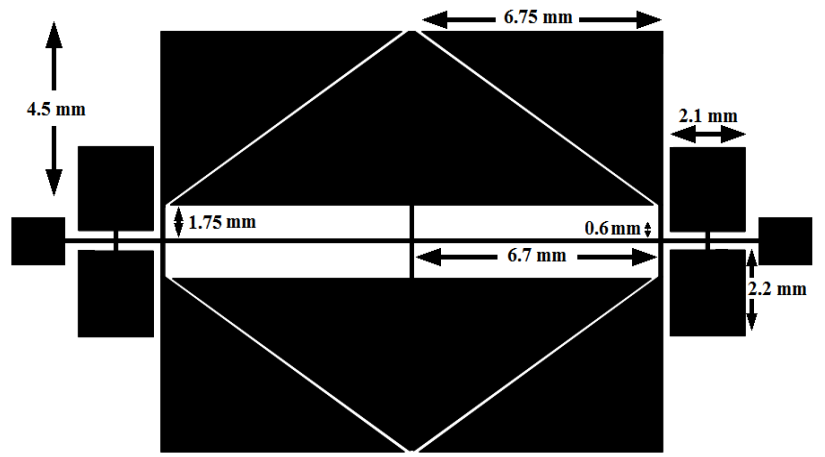

(a)

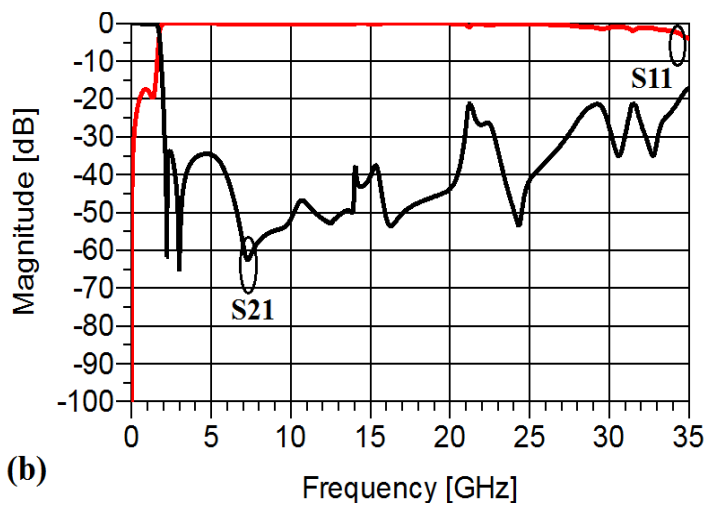

Fig. 9. The configuration of the proposed LPF. (b) The frequency response of the proposed LPF.

in the passband are obtained. Finally, a compact LPF with $-3 \mathrm{~dB}$ cut-off frequency of $1.8 \mathrm{GHz}$, a sharp transition band and an ultra-wide stopband $(32.63 \mathrm{GHz})$ is designed, as shown in Fig. 10(c).

\section{The Results of Simulation and Measurement}

The photograph of the proposed LPF is depicted in Fig. 11(a). The presented LPF has been designed, constructed and measured. The proposed LPF has been fabricated on RO4003 substrate with a thickness of $0.508 \mathrm{~mm}$ and the permittivity of 3.38. The results of simulation and measurement of the designed LPF have been carried out by utilizing an EM-simulator ADS based on the method of moments and a HP8757A network analyzer, respectively. The frequency responses of the proposed LPF have been shown in Fig. 11(b). As it can be observed, the operating frequency of the filter has been located on $1.8 \mathrm{GHz}$. According to the measurement results, in the whole passband region the insertion loss is approximately zero and also in this band the return loss is almost $17.3 \mathrm{~dB}$. As it is observed, close to the operating frequency two transmission zeros with attenuation levels of $-61.086 \mathrm{~dB}$ and $-64.247 \mathrm{~dB}$ exist causing a sharp transition band. Thanks to these TZs, a sharp roll-off rate equal to $228(\mathrm{~dB} / \mathrm{GHz})$ has been obtained. The stopband region suppresses spurious frequencies from 1.94 to $34.556 \mathrm{GHz}$ with corresponding rejection level of $-21.2 \mathrm{~dB}$. Moreover, in the
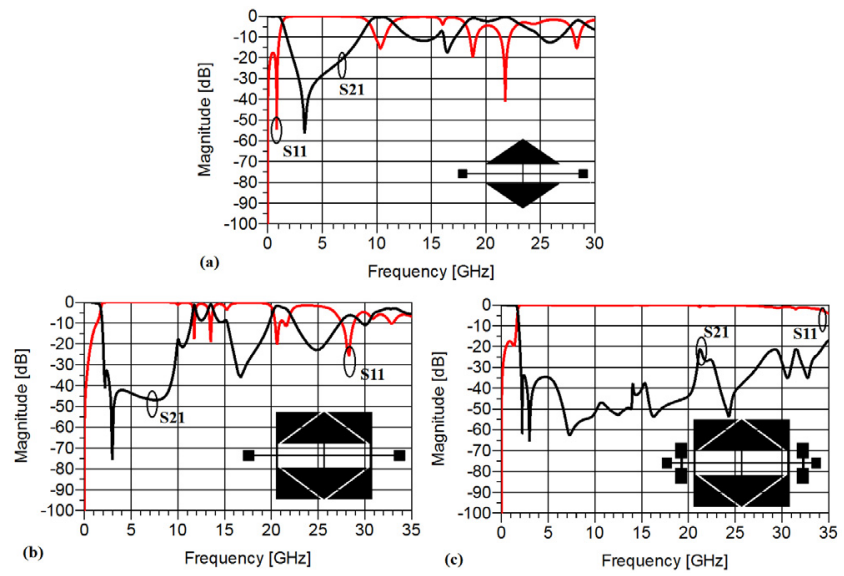

Fig. 10. The frequency response of (a) Resonator 1. (b) Resonators 1 and 2. (c) Resonators 1, 2 and the first suppressing cell.
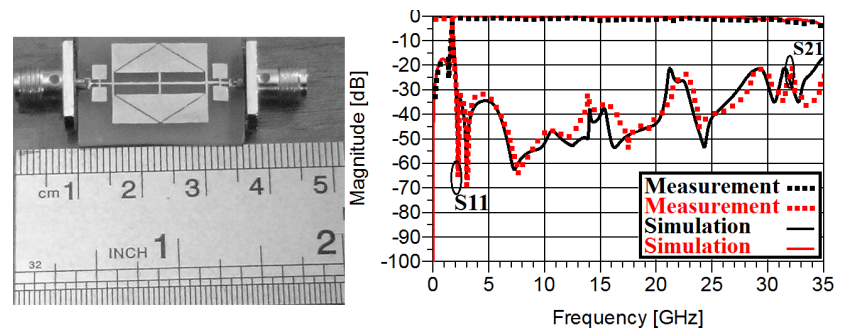

Fig. 11. The photograph of the proposed LPF and its frequency response.

\begin{tabular}{|c|c|c|c|c|c|c|}
\hline Ref. & $\mathrm{RO}(\zeta)$ & $\mathrm{RSB}$ & $\mathrm{SF}$ & NCS & $\mathrm{AF}$ & $\mathrm{FOM}$ \\
\hline$[1]$ & 36.3 & 1.323 & 1.5 & $0.079 \times 0.079$ & 1 & 11543 \\
\hline$[2]$ & 37 & 1.15 & 2 & $0.280 \times 0.076$ & 1 & 3999 \\
\hline$[3]$ & 30 & 1.25 & 1.5 & $0.080 \times 0.080$ & 1 & 8789 \\
\hline$[4]$ & 74 & 1.19 & 2 & $0.114 \times 0.105$ & 1 & 14713 \\
\hline$[5]$ & 95 & 1.4 & 2 & $0.214 \times 0.104$ & 1 & 11951 \\
\hline$[6]$ & 130 & 0.933 & 2 & $0.227 \times 0.089$ & 2 & 6004 \\
\hline$[7]$ & 200 & 1.36 & 2 & $0.801 \times 0.374$ & 1 & 1815.9 \\
\hline$[8]$ & 82 & 1.28 & 2.5 & $0.110 \times 0.220$ & 1 & 10842 \\
\hline$[9]$ & 37 & 1.65 & 1.5 & $0.111 \times 0.091$ & 1 & 9065 \\
\hline$[10]$ & 61.6 & 1.44 & 1 & $0.272 \times 0.236$ & 1 & 1386 \\
\hline$[11]$ & 62 & 1.72 & 3 & $0.310 \times 0.240$ & 1 & 4430 \\
\hline$[14]$ & 185 & 1.666 & 2.1 & $0.227 \times 0.177$ & 1 & 16181 \\
\hline $\begin{array}{c}\text { This } \\
\text { Work }\end{array}$ & $\mathbf{2 2 8}$ & $\mathbf{1 . 7 8}$ & $\mathbf{2 . 1}$ & $\mathbf{0 . 2 2 9} \times \mathbf{0 . 1 4 0}$ & $\mathbf{1}$ & $\mathbf{2 6 5 8 3 . 4}$ \\
\hline
\end{tabular}

Tab. 1. The comparison of the abilities of the proposed LPF and previous works.

rejection band a flat return loss has been obtained, which verifies a good out-band performance. The circuit size of the demonstrated filter is about $20.8 \mathrm{~mm} \times 12.75 \mathrm{~mm}$. Tab. 1 shows the performance comparison of the other published works and the proposed LPF.

In Tab. 1 the roll-off rate $\xi$ is defined as follows:

$$
\xi=\frac{\alpha_{\max }-\alpha_{\min }}{f_{\mathrm{S}}-f_{\mathrm{C}}} \quad[\mathrm{dB} / \mathrm{GHz}] .
$$

In this equation $\alpha_{\max }$ is the $40 \mathrm{~dB}$ attenuation point, $\alpha_{\min }$ is the $3 \mathrm{~dB}$ attenuation point, $f_{\mathrm{s}}$ is the $40 \mathrm{~dB}$ stop-band frequency, and $f_{\mathrm{C}}$ is the $-3 \mathrm{~dB}$ cutoff frequency. 
The relative stop-band bandwidth $R S B$ is defined as shown below:

$$
R S B=\frac{\text { stop-band bandwidth }(-20 \mathrm{~dB})}{\text { stop-band center frequency }} .
$$

The suppression factor $S F$ is defined as shown in (35). For example, when the stop-band suppression is $21 \mathrm{~dB}$, the corresponding $S F$ will be 2.1 .

$$
S F=\frac{\text { stop-band } \text { suppression }}{10 \mathrm{~dB}} .
$$

The normalized circuit size $N C S$ is given by:

$$
N C S=\frac{\text { physical size }(\text { length } \times \text { width })}{\lambda_{\mathrm{g}}^{2}}
$$

where $\lambda_{\mathrm{g}}$ is the guided wavelength at $-3 \mathrm{~dB}$ cut-off frequency.

The architecture factor $A F$ denotes the circuit complexity. When we have a two-dimensional design, we define $A F=1$. Similarly, for three-dimensional designs, we have $A F=2$. follows:

At the end, the figure-of-merit FOM is defined as

$$
F O M=\frac{\xi \cdot R S B \cdot S F}{N C S \cdot A F}
$$

Based on the above definitions, it is easily understood that the proposed filter has a figure-of-merit equal to 26583.4

As it can be seen, the transition band sharpness of the proposed structure is better than the other published articles, which is the result of the combination of the first and second resonators. As the result of employing the shown suppressing unit in Fig. 7(a), an acceptable relative stopband bandwidth RSB equal to 1.78 has been achieved. The closest figures to this have been reported in [11] and [14] (1.72 and 1.666, respectively). The suppressing cells reject spurious frequencies with a suppressing level of $21 \mathrm{~dB}$, which is to some extent similar to the other works, except for the reported suppressing factors in [1], [3], [9], [10] as their rejecting levels are less than the others, considerably. As it can be seen, the proposed filter, despite occupying $265.2 \mathrm{~mm}^{2}$ at operating frequency of $1.8 \mathrm{GHz}$, has brought about an acceptable FOM equal to 26583.4, which is much more than the previous works.

\section{Conclusion}

A microstrip LPF with compact size and ultra-wide stopband has been designed, fabricated and measured. Simulation and measurement results are in good agreement. The proposed filter is consisted of two resonators with coupled triangular patches and four suppressing cells. To clarify the importance of utilizing each line of the used resonators, the equations of their $S_{21}$ and $S_{11}$ based on their equivalent LC circuit have been calculated.

\section{References}

[1] WANG, J., XU, L. J., ZHAO, S., GUO, Y. X., WU, W. Compact quasi-elliptic microstrip lowpass filter with wide stopband. Electronics Letters, 2010, vol. 46, no. 20, p. 1384-1385. DOI: 10.1049/el.2010.1569

[2] LUO, S., ZHU, L., SUN, S. Stopband-expanded low-pass filters using microstrip coupled-line hairpin units. IEEE Microwave and Wireless Components Letters, 2008, vol. 18, no. 8, p. 506-508. DOI: 10.1109/LMWC.2008.2001004

[3] WEI, X. B., WANG, P., LIU, M. Q., SHI, Y. Compact widestopband lowpass filter using stepped impedance hairpin resonator with radial stubs. Electronics Letters, 2011, vol. 47, no. 15, p. 862-863. DOI: 10.1049/el.2011.1414

[4] LI, L., LI, F. Z., MAO, F. J. Compact lowpass filters with sharpand expanded stopband using stepped impedance hairpin units. IEEE Microwave and Wireless Components Letters, 2010, vol. 20, no. 6, p. 310-312. DOI: 10.1109/LMWC.2010.2047457

[5] VELIDI, V. K., SANYAL, S. Sharp roll-off lowpass filter with wide stopband using stub-loaded coupled-line hairpin unit. IEEE Microwave and Wireless Components Letters, 2011, vol. 21, no. 6, p. 301-303. DOI: 10.1109/LMWC.2011.2132120

[6] MANDAL, M. K., MANDAL, P., SANYAL, S., CHAKRABARTY, A. Low insertion-loss, sharp rejection and compact microstrip lowpass filter. IEEE Microwave and Wireless Components Letters, 2006, vol. 16, no. 11, p. 600-602. DOI: 10.1109/LMWC.2006.884777

[7] GOMEZ-GARCIA, R., SANCHEZ-SORIANO, M. A., SANCHEZ RENEDO, M., et al. Extended-stopband microstrip lowpass filter using rat-race directional couplers. Electronics Letters, 2013, vol. 49, no. 4, p. 272-274. DOI: 10.1049/el.2012.4245

[8] WANG, C. J., LIN, C. H. Compact lowpass filter with sharp transition knee by utilising a quasi- $\pi$-slot resonator and open stubs. IET Microwaves Antennas and Propagation, 2010, vol. 4, no. 4, p. 512-517. DOI: 10.1049/iet-map.2009.0001

[9] WANG, J., CUI, H., ZHANG, G. Design of compact microstrip lowpass filter with ultra-wide stopband. Electronics Letters, 2012, vol. 48, no. 14, p. 854-856. DOI: 10.1049/el.2012.1362

[10] WEI, F., CHEN, L., SHI, X. W., HUANG, Q. L., WANG, X. H. Compact lowpass filter with wide stop-band using coupled-line hairpin unit. Electronics Letters, 2010, vol. 46, no. 1, p. 88-90. DOI: $10.1049 / \mathrm{el} .2010 .2411$

[11] MA, K., YEO, K. S. New ultra-wide stopband low-pass filter using transformed radial stubs. IEEE Transactions on Microwave Theory and Techniques, 2011, vol. 59, no. 3, p. 604-611. DOI: 10.1109/TMTT.2010.2095031

[12] ABDIPOUR, AS., ABDIPOUR, AR., LOTFI, S. A lowpass filter with sharp roll-off and high relative stopband bandwidth using asymmetric high-low impedance patches. Radioengineering, 2015, vol. 24, no. 3, p. 712-716. DOI: 10.13164/re.2015.0712

[13] NOURITABAR, A. R., ABDIPOUR, AS., ABDIPOUR, AR. A design of low-pass filter with wide stopband and sharp roll-off rate using series LC tanks resonator. Applied Computational Electromagnetics Society (ACES) Journal, 2016, vol. 31, no. 11, p. 1343-1350. ISSN: 1054-4887

[14] ABDIPOUR, AR., ABDIPOUR, AS. Compact microstrip lowpass filter with an ultra-wide stopband and sharp transition band using T-shaped and polygon resonators. Progress In Electromagnetics 
Research C, 2017, vol. $74, \quad$ p. 51-61. DOI: 10.2528/PIERC16121904

[15] ABDIPOUR, AR., ABDIPOUR, AS., LORESTANI, F. A compact microstrip lowpass filter with sharp roll-off rate and ultra-wide stopband employing coupled polygon patches. Progress In Electromagnetics Research C, 2017, vol. 76, p. 171-186. DOI: 10.2528/PIERC17043003

[16] HONG, J. S., LANCASTER, M. J. Microstrip Filters for $R F /$ Microwave Applications. $1^{\text {st }}$ ed. John Wiley \& Sons, Inc., 2001. ISBN 0-471-22161-9. DOI:10.1002/0471221619

\section{About the Authors ...}

Ashkan ABDIPOUR received the B.S. in Electronics Engineering from Islamic Azad University, Kermanshah Branch, Kermanshah, Iran, in 2009 and the M.S degree from Razi University, Kermanshah, Iran, in 2013. His research interest includes microwave and millimeter wave devices and circuits.

Arash ABDIPOUR received the B.S. in Electronics Engineering from Islamic Azad University, Kermanshah Branch, Kermanshah, Iran, in 2009 and Master's degree in Electronics Engineering from the Kermanshah-science and research University of Kermanshah Branch, Kermanshah, Iran, in 2013. His research interest includes microwave and millimeter wave devices and circuits.

Amir KHOSRAVI received the B.S. in Electronics Engineering from the Islamic Azad University, Kermanshah Branch, Kermanshah, Iran, in 2009 and Master's degree in Electronics Engineering from the Azad University of Sanandaj, Kordestan, Iran, in 2013. His research interest includes microstrip lowpass filters. 